\title{
Pharmacokinetics of levamisole in sheep after intravenous administration
}

\author{
M.Fernández*,J.J.García*, M.Sierra*,M.J.Diez* and M.T.Terán ${ }^{* \dagger}$
}

\begin{abstract}
The pharmacokinetics of levamisole at doses of $5,7.5$ and $10 \mathrm{mg} / \mathrm{kg}$ were determined after its intravenous administration to eighteen healthy Merino sheep. Using compartmental analysis, the disposition of the drug best fitted a two-compartmental open model. The mean values for the compartmental volume of distribution at steady state $\left(\mathrm{V}_{\mathrm{ss}}\right)$ were $2.034 \pm 0.231,2.347 \pm 0.720$ and $2.001 \pm 0.367 \mathrm{l} / \mathrm{kg}$ for each dose, respectively, and values obtained using the statistical moment theory were $2.141 \pm 0.269,2.390$ \pm 0.536 and $2.140 \pm 0.345 \mathrm{l} / \mathrm{kg}$ for each dose, respectively. There were no dose-related differences (one-way ANOVA) in the constants describing distribution and elimination phases $\left(\alpha\right.$ and $\beta$ ) or $V_{v}$, but significant differences were detected in the total body clearance ( $\mathrm{Cl}$ ) and the area under the plasma concentration-time curve (AUC). After non-compartmental analysis, no significant differences were found when the parameters $\lambda$ (the linear terminal slope) and $V_{s s}$ were compared, but significant differences were detected in $\mathrm{Cl}$ and $\mathrm{AUC}$. There were no significant differences between the values obtained using the compartmental and noncompartmental analysis when $\lambda-\beta, \mathrm{Cl}, \mathrm{V}_{\mathrm{ss}}$ and $\mathrm{AUC}$ were compared.

(New Zealand Veterinary Journal 45, 63-66, 1997.)
\end{abstract}

\section{Introduction}

Levamisole, $l$-2,3,5,6-tetrahydro-6-phenylimidazo(2,1-b) thiazole, is a synthetic anthelmintic used in veterinary and human medicine which has been shown to influence the immune system. The drug is used in sheep against a wide range of gastro-intestinal worms and lungworms ${ }^{(1)(2)}$, and it is available as a formulation for oral, subcutaneous and intramuscular administration. Moreover, it may be used in sheep and other animals as an immunostimulant ${ }^{(3)(4)}$.

The purpose of the present study was to establish the compartmental and non-compartmental pharmacokinetics of levamisole in sheep after intravenous administration. No research in this area has been carried out on sheep and the available pharmacokinetic data are incomplete.

\section{Materials and Methods}

\section{Animals}

Eighteen healthy Merino sheep were used. All animals were males of about 6 months old and weighed from 22 to $30 \mathrm{~kg}$. They were maintained indoors on a hay and concentrates diet.

\footnotetext{
* Department of Physiology, Pharmacology and Toxicology, Veterinary Faculty, University of León, Campus de Vegazana, s/n. 24071 León, Spain. † Author for correspondence.
}

\section{Treatment and blood sampling}

The sheep were randomly divided into three groups of six animals each, which received $5,7.5$ and $10 \mathrm{mg} / \mathrm{kg}$ of levamisole, respectively, as levamisole $\mathrm{HCl}$ (Sigma) in aqueous solution. Whole blood was collected by jugular venipuncture into heparinised vials (Vasocan, Braunüle, Braun Melsungen A.G.) immediately prior to the administration of levamisole and at $5,10,15,20,25,30,60,90$, $120,150,180,240,300,360$ and 480 minutes after intravenous administration. Plasma was separated immediately by centrifugation and stored at $-20^{\circ} \mathrm{C}$ until analysed.

\section{Analytical method}

Plasma levamisole concentration was determined by high-performance liquid chromatography (HPLC) with ultraviolet detection as previously described ${ }^{(5)}$. The lowest detectable concentration of levamisole in plasma was $0.08 \mu \mathrm{g} / \mathrm{ml}$.

\section{Pharmacokinetic analysis}

Individual and mean plasma levamisole concentration-time data were analysed using both compartmental and non-compartmental methods. For the compartmental analysis, the iterative weighted nonlinear least-squares regression program PCNONLIN ${ }^{(6)}$ was used and initial estimates of the parameters were determinated by JANA ${ }^{(7)}$. The best pharmacokinetic model (one-, two- and three-compartment) was determined by application of Akaike's information criterion ${ }^{(8)}$ and graphical analysis of weighted residuals. A two-compartment open model was selected and the equation used to describe levamisole pharmacokinetics was:

$$
C=A \cdot e^{-\alpha t}+B \cdot e^{-\beta t}
$$

where $\mathrm{C}$ is the plasma concentration of levamisole, $\mathrm{A}$ and $\mathrm{B}$ are the zero-time plasma drug concentration intercepts for the biphasic disposition curve, and $\alpha$ and $\beta$ are the first order constants describing the slopes of the distribution and elimination phases, respectively. These values were obtained using initial estimates. The other parameters were calculated by the standard methods of Gibaldi and Perrier ${ }^{99}$. 
The model independent pharmacokinetic parameters were calculated by using expressions based on the statistical moments theory ${ }^{(10)}$ and on formulae described by Gibaldi and Perrier ${ }^{(9)}$. The linear terminal slope $(\lambda)$ was calculated by least squares regression of the logarithm of plasma concentration versus time curve over the terminal elimination phase. The area under the plasma concentration-time curve from time zero to the last time point $\left(\mathrm{AUC}_{0.1}\right)$ was calculated by the trapezoidal rule, and the total area under the plasma concentration-time curve (AUC) by adding $\mathrm{AUC}_{0-t}$ to the residual area $\mathrm{AUC}_{1-\infty}$ (calculated by the quotient of $\mathrm{C}_{1}$, the last experimental plasma concentration and the terminal slope, $\lambda$ ). The area under the curve of the product of the time (t) and the plasma drug concentration (C) versus time ( $t$ ) from time zero to infinity (AUMC) was calculated using the linear trapezoidal rule with extrapolation to infinity. The mean residence time (MRT) was determined by the equation:

\section{MRT $=$ AUMC/AUC}

The total body clearance $(\mathrm{Cl})$ was calculated from the quotient of the dose (D) and AUC. The terminal volume of distribution $\left(\mathrm{V}_{\mathrm{a}}\right)$ was calculated from the ratio of the total body clearance $(\mathrm{Cl})$ and the terminal slope $(\lambda)$. The volume of distribution at steady state $\left(\mathrm{V}_{\mathrm{ss}}\right)$ was determined by the equation:

$$
\mathrm{V}_{\mathrm{ss}}=\mathrm{MRT} .(\mathrm{D} / \mathrm{AUC})
$$

\section{Statistical analysis}

The pharmacokinetic parameters determined by compartmental and non-compartmental models were compared for statistical significance by using the one-way and two-way analysis of variance (ANOVA). When the results were significant, the Duncan test ${ }^{(11)}$ was used to evaluate differences between data sets and the probability $p \leq 0.05$ was taken as the level of significance for all analyses.

\section{Results}

The mean and standard deviation levamisole plasma concentration-time profiles and the best fitting curves for the three doses are shown in Figure 1. The values of the pharmacokinetic parameters determined by both compartmental and non-compartmental analysis are given in Tables I and II, respectively.

\section{Compartmental analysis}

After intravenous administration, the pharmacokinetics were better described by a two-compartmental open model for all sheep. The mean values for the early $\alpha$ phase were $0.0554 \pm$ $0.0257,0.0594 \pm 0.0116$ and $0.0616 \pm 0.0296 \mathrm{~min}^{-1}$, respectively, for the three doses; those for the terminal $\beta$ phase were $0.0075 \pm 0.0008 \mathrm{~min}^{-1}(5 \mathrm{mg} / \mathrm{kg}), 0.0089 \pm 0.0016 \mathrm{~min}^{-1}(7.5$ $\mathrm{mg} / \mathrm{kg})$ and $0.0072 \pm 0.0021 \mathrm{~min}^{-1}(10 \mathrm{mg} / \mathrm{kg})$. Moreover, the values obtained for $\mathrm{V}$ were practically the same for the three doses. One way analysis of variance (ANOVA) of dose showed no significant differences in $\alpha, \beta$ and $V_{s s}$.

AUC mean values increased with doses. However, Duncan test analysis indicated statistically significant differences between AUC values for the $10 \mathrm{mg} / \mathrm{kg}$ dose and lower doses. Furthermore, significant differences were detected in clearance between the $7.5 \mathrm{mg} / \mathrm{kg}$ dose $(0.0256 \pm 0.0076 \mathrm{l} / \mathrm{kg} . \mathrm{min})$ and the other doses $(0.0193 \pm 0.0017 \mathrm{l} / \mathrm{kg}$. $\mathrm{min}$ for the $5 \mathrm{mg} / \mathrm{kg}$ dose and 0.0169 $\pm 0.0037 \mathrm{l} / \mathrm{kg} \cdot \mathrm{min}$ for the the $10 \mathrm{mg} / \mathrm{kg}$ dose).

\section{Non-compartmental analysis}

The mean values for $\lambda$ were $0.0078 \pm 0.0004 \mathrm{~min}^{-1}$ for the 5 $\mathrm{mg} / \mathrm{kg}$ dose, $0.0086 \pm 0.0013 \mathrm{~min}^{-1}$ for the $7.5 \mathrm{mg} / \mathrm{kg}$ dose and $0.0067 \pm 0.0020 \mathrm{~min}^{-1}$ for the $10 \mathrm{mg} / \mathrm{kg}$ dose. Moreover,

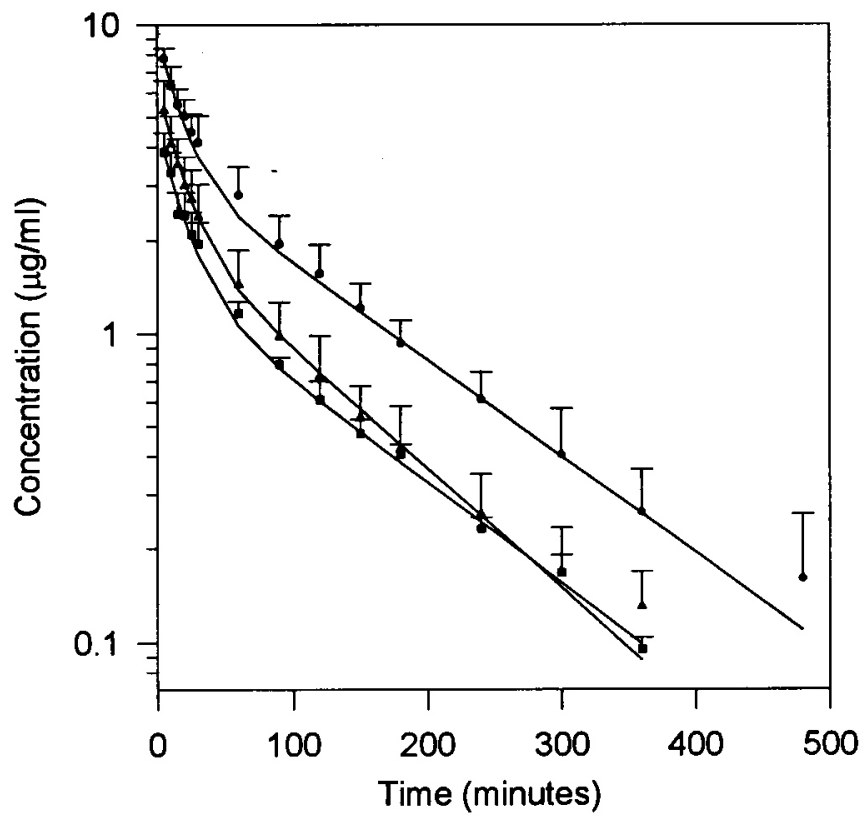

Figure 1. Mean plasma concentration in six sheep after intravenous administration of levamisole at doses of $5(\square)$, $7.5(\Delta)$ and $10(O) \mathrm{mg} / \mathrm{kg}$. Continuous lines are fitted by the PCNONLIN program.

those corresponding to $\mathrm{V}_{\mathrm{ss}}$ were $2.141 \pm 0.269,2.390 \pm 0.536$ and $2.140 \pm 0.345 \mathrm{l} / \mathrm{kg}$ for the three doses, respectively. There were no significant differences in the values of $\lambda$ and $V_{\mathrm{ss}}$ for the three doses.

In the same way as in the compartmental analysis, the AUC mean values increased with doses and statistically significant differences were found between the values for the $10 \mathrm{mg} / \mathrm{kg}$ dose and lower doses in ANOVA. Furthermore, the mean values of clearance were of $0.0197 \pm 0.0017 \mathrm{l} / \mathrm{kg} \cdot \mathrm{min}(5 \mathrm{mg}$ / $\mathrm{kg}), 0.0260 \pm 0.0076 \mathrm{l} / \mathrm{kg} \cdot \min (7.5 \mathrm{mg} / \mathrm{kg})$ and $0.0172 \pm$ $0.0040 \mathrm{l} / \mathrm{kg} \cdot \mathrm{min}(10 \mathrm{mg} / \mathrm{kg})$. There were significant differences between the $7.5 \mathrm{mg} / \mathrm{kg}$ dose and the other doses.

Finally, there were no significant differences between the values obtained using the compartmental and noncompartmental analysis when $\lambda-\beta, \mathrm{Cl}, \mathrm{V}_{\mathrm{ss}}$ and $\mathrm{AUC}$ were compared.

\section{Discussion}

Levamisole showed a two-compartmental disposition in sheep. This was also reported in pigs ${ }^{(12)}$ and in pigs and goats ${ }^{(1.3)}$ after the intravenous administration of $5 \mathrm{mg} / \mathrm{kg}$. Likewise, this same fact was reported in rabbits ${ }^{(14)}$ after intravenous administration of $12.5,16$ and $20 \mathrm{mg} / \mathrm{kg}$. However, it has been shown that in dogs levamisole followed a one-compartmental pattern after the intravenous administration of $10 \mathrm{mg} / \mathrm{kg}^{(15)}$. Data concerning levamisole pharmacokinetic behaviour after intravenous administration in sheep have not been found in bibliographic searches.

The mean values obtained for the $\alpha\left(0.0554-0.0616 \mathrm{~min}^{-1}\right)$ and $\beta$ parameters $\left(0.0072-0.0089 \mathrm{~min}^{-1}\right)$ were higher than those obtained in pigs ${ }^{(12)}\left(\alpha=0.0245 \mathrm{~min}^{-1}\right.$ and $\beta=0.0013$ $\left.\min ^{-1}\right)$ but they were lower than those obtained in rabbits ${ }^{(14)}$ ( $\alpha$ ranged from 0.1019 to $0.1282 \mathrm{~min}^{-1}$ and $\beta$ from 0.0114 to $0.0126 \mathrm{~min}^{-1}$ ). 
Table I. Pharmacokinetic parameters (mean \pm standard deviation) obtained by compartmental analysis in six sheep after intravenous administration of levamisole

\begin{tabular}{|c|c|c|c|}
\hline & \multicolumn{3}{|c|}{ Dose $(\mathrm{mg} / \mathbf{k g})$} \\
\hline & 5 & 7.5 & 10 \\
\hline $\mathrm{A}(\mu \mathrm{g} / \mathrm{ml})^{y, x}$ & $3.199 \pm 0.852$ & $4.208 \pm 1.341$ & $5.846 \pm 0.461$ \\
\hline $\mathrm{B}(\mu \mathrm{g} / \mathrm{ml})^{y, z}$ & $1.480 \pm 0.276$ & $2.169 \pm 0.811$ & $3.474 \pm 1.376$ \\
\hline$\alpha\left(\min ^{-1}\right)^{\omega}$ & $0.0554 \pm 0.0257$ & $0.0594 \pm 0.0116$ & $0.0616 \pm 0.0296$ \\
\hline$\beta\left(\min ^{-1}\right)^{w}$ & $0.0075 \pm 0.0008$ & $0.0089 \pm 0.0016$ & $0.0072 \pm 0.0021$ \\
\hline$k_{12}\left(\min ^{-1}\right)^{w}$ & $0.0217 \pm 0.0142$ & $0.0221 \pm 0.0083$ & $0.0243 \pm 0.0138$ \\
\hline$k_{21}\left(\min ^{-1}\right)^{w}$ & $0.0233 \pm 0.0102$ & $0.0258 \pm 0.0060$ & $0.0287 \pm 0.0156$ \\
\hline $\mathrm{k}_{10}\left(\min ^{-1}\right)^{\mathrm{w}}$ & $0.0179 \pm 0.0033$ & $0.0204 \pm 0.0021$ & $0.0157 \pm 0.0036$ \\
\hline AUC $(\mu \mathrm{g} \cdot \min / \mathrm{ml})^{y . z}$ & $261.3 \pm 24.0$ & $313.3 \pm 84.1$ & $612.5 \pm 123.2$ \\
\hline $\mathrm{V}_{\mathrm{c}}(\mathrm{l} / \mathrm{kg})^{\mathrm{w}}$ & $1.105 \pm 0.227$ & $1.257 \pm 0.360$ & $1.090 \pm 0.151$ \\
\hline$V_{p}(l / k g)^{w}$ & $0.9291 \pm 0.1519$ & $1.090 \pm 0.465$ & $0.9112 \pm 0.2810$ \\
\hline $\mathrm{V}_{\mathrm{ss}}(1 / \mathrm{kg})^{\mathrm{w}}$ & $2.034 \pm 0.231$ & $2.347 \pm 0.720$ & $2.001 \pm 0.367$ \\
\hline$V_{a}(l / k g)^{w}$ & $2.572 \pm 0.260$ & $2.981 \pm 1.129$ & $2.492 \pm 0.686$ \\
\hline $\mathrm{Cl}(1 / \mathrm{kg} \cdot \min )^{x . \mathrm{x}}$ & $0.0193 \pm 0.0017$ & $0.0256 \pm 0.0076$ & $0.0169 \pm 0.0037$ \\
\hline$t_{1 / 2 \alpha}(\min )^{w}$ & $14.66 \pm 5.75$ & $12.01 \pm 2.09$ & $15.81 \pm 12.51$ \\
\hline$t_{1 / 2 \mathrm{~B}}(\min )^{\mathrm{w}}$ & $92.90 \pm 10.23$ & $80.12 \pm 12.30$ & $105.2 \pm 36.1$ \\
\hline$t_{1 / 2 k 13}(\min )^{w}$ & $39.76 \pm 7.17$ & $34.21 \pm 3.40$ & $46.32 \pm 12.35$ \\
\hline$C_{n}(\mu g / m l)^{x . y . j}$ & $4.679 \pm 0.919$ & $6.377 \pm 1.744$ & $9.320 \pm 1.279$ \\
\hline
\end{tabular}

One-way ANOVA results: "no statistically significant differences; the other superscripts denote significant differences (Duncan test) between: $\times 5$ and $7.5 \mathrm{mg} / \mathrm{kg},{ }^{5} 5$ and $10 \mathrm{mg} / \mathrm{kg},{ }^{27.5}$ and $10 \mathrm{mg} / \mathrm{kg}$.

Table II. Pharmacokinetic parameters (mean \pm standard deviation) obtained by non-compartmental analysis in six sheep after intravenous administration of levamisole

\begin{tabular}{|c|c|c|c|}
\hline & \multicolumn{3}{|c|}{ Dose $(\mathrm{mg} / \mathbf{k g})$} \\
\hline & 5 & 7.5 & 10 \\
\hline$\lambda\left(\min ^{-1}\right)^{v, w}$ & $0.0078 \pm 0.0004$ & $0.0086 \pm 0.0013$ & $0.0067 \pm 0.0020$ \\
\hline AUC $(\mu \mathrm{g} \cdot \mathrm{min} / \mathrm{ml})^{\mathrm{v} \cdot \mathrm{y} \cdot \mathrm{z} .}$ & $255.0 \pm 22.2$ & $308.3 \pm 82.0$ & $606.5 \pm 131.2$ \\
\hline AUMC $\left(\mu \mathrm{g} \cdot \mathrm{min}^{2} / \mathrm{ml}\right)^{y, x}$ & $27555.1 \pm 2096.9$ & $29417.0 \pm 10059.2$ & $79263.0 \pm 29679.2$ \\
\hline MRT $(\min )^{y, z}$ & $108.3 \pm 6.5$ & $93.84 \pm 11.14$ & $127.5 \pm 22.3$ \\
\hline $\mathrm{Cl}(\mathrm{l} / \mathrm{kg} \cdot \min )^{x, y_{2}, 2}$ & $0.0197 \pm 0.0017$ & $0.0260 \pm 0.0076$ & $0.0172 \pm 0.0040$ \\
\hline$V_{s s}(1 / k g)^{v . w}$ & $2.141 \pm 0.269$ & $2.390 \pm 0.536$ & $2.140 \pm 0.345$ \\
\hline$V_{a}(1 / k g)^{v, w}$ & $2.527 \pm 0.234$ & $3.064 \pm 1.025$ & $2.659 \pm 0.632$ \\
\hline
\end{tabular}

Two-way ANOVA results: "no statistically significant differences with compartmental parameters. One-way ANOVA results: "no statistically significant differences; the other superscripts denote significant differences (Duncan test) between $\times 5$ and $7.5 \mathrm{mg} / \mathrm{kg},{ }^{y} 5 \mathrm{and} 10 \mathrm{mg} / \mathrm{kg},{ }^{x} .5 \mathrm{and}$ $10 \mathrm{mg} / \mathrm{kg}$.

The $\mathrm{V}_{\mathrm{ss}}$ mean values of levamisole obtained in the present study are between those obtained in $\operatorname{dogs}^{(15)}(1.42 \mathrm{l} / \mathrm{kg})$ and those determined in rabbits ${ }^{(14)}(2.7-3.91 / \mathrm{kg})$. Moreover, the mean values of $\mathrm{Cl}$ obtained are similar to those determined in $\operatorname{dog} s^{(15)}$. However, they were lower than those obtained in rabbits ${ }^{(14)}$.

Finally the mean values of $k_{12}, k_{21}$ and $k_{10}$ for each dose, as well as the fact that the $\mathrm{V}_{\mathrm{ss}}$ is higher than the physiological volume, show that levamisole in sheep has a greater tendency to distribute between central and peripheral compartments than to eliminate, and it is retained in some tissue. Distribution studies in several species ${ }^{(16)}$ showed that the organs involved in the metabolism and excretion of levamisole, namely the liver and kidney, contained the highest levels of drug. Other authors have also found very high values of distribution volumes for levamisole in humans ${ }^{(17)}$ and different animal species, i.e. sheep and goats ${ }^{(18)}$, pigs ${ }^{(13)}, \operatorname{dogs}^{(15)}$ and rabbits ${ }^{(14)}$.

\section{Acknowledgments}

This research was supported by Iberdrola, S.A. 


\section{References}

(1) Walley, JK. Tetramisole (dl 2,3,5,6-tetrahydro-6-phenyl-imidazo (2,1b) thiazole hydrochloride, Nilverm) in the treatment of gastro-intestinal worms and lungworms in domestic animals. Veterinary Record 78, 406$8,1966$.

(2) Thienpont D, Vanparijs OFJ, Raeymaekers AHM, Vandenberk J, Demoen PJA, Allewijn FTN, Marsboom RPH, Niemegeers CJE, Schellekens KHL, Janssen PAJ. Tetramisole (R 8299), a new, potent broad spectrum anthelmintic. Nature 209, 1084-6, 1966.

(3) Hogarth-Scott RS, Liardet DM, Morris PJ. Levamisole vaccine combination. 1. Heightened antibody response. Australian Veterinary Journal $56,285-8,1980$.

(4) Flesh J, Harel W, Nelken D. Immunopotentiating effect of levamisole in the prevention of bovine mastitis, fetal death and endometritis. Veterinary Record $111,56-9,1982$.

(5) García JJ, Diez MJ, Sierra M, Terán MT. Determination of levamisole by HPLC in plasma in the presence of heparin and pentobarbital. Journal of Liquid Chromatography 13.743-9, 1990.

(6) Metzler CM, Weiner DL. PCNONLIN User's Guide. Version 3.0. Statistical Consultants, Lexington, 1989.

(7) Dunne A. JANA: A new iterative polyexponential curve stripping program. Computer Methods Programs Biomedicine 20, 269-75, 1985

(8) Yamaoka K, Nakagawa T, Uno T. Application of a Akaike's information criterion (AIC) in the evaluation of linear pharmacokinetic equations. Journal of Pharmacokinetics and Biopharmaceutics 6, 165-75, 1978.

(9) Gibaldi M, Perrier D. Multicompartment models. In: Pharmacokinetics. 2nd Edition. Pp 45-111. Marcel Dekker, New York, 1982.

(10) Yamaoka K, Nakagawa T, Uno T. Statistical moments in pharmacokinetics. Journal of Pharmacokinetics and Biopharmaceutics 6, 547-58, 1978.
(11) Steel RG, Torrie JH. Multiple comparison. In: Principles and Procedures of Statistics. Pp 106-139. Mc Graw-Hill Book Company Inc. New York, 1960.

(12) Galtier P, Escoula L, Alviniere M. Pharmacokinetics of $\left[{ }^{3} \mathrm{H}\right]$ levamisole in pigs after oral and intramuscular administration. American Journal of Veterinary Research 44, 583-7, 1983.

(13) Nielsen P, Rasmussen F. Pharmacokinetics of levamisole in goats and pigs. In: Ruckebusch Y, Toutain PL, Koritz GD (eds). Veterinary Pharmacology and Toxicology. Pp 241-4. MTP Press Limited, Lancaster, 1983.

(14) García JJ, Diez MJ, Sierra M, Terán MT. Pharmacokinetics of levamisole in rabbits after intravenous administration. Journal of Veterinary Pharmacology and Therapeutics 15, 85-90, 1992.

(15) Watson ADJ, Sangster NC. Church DB, Van Gogh H. Levamisole pharmacokinetics and bioavailability in dogs. Research in Veterinary Science $45,411-3,1988$.

(16) Graziani G, De Martin GL. Pharmacokinetic studies on levamisole. Absorption, distribution, excretion and metabolism of levamisole in animals. A review. Drugs under Experimental Clinical Research 2, 22133, 1977

(17) Luyckx M, Rousseau F, Cazin M, Brunet C, Cazin JC, Haguenoer JM, Devulder B, Lesieur I, Lesieur D, Gosselin P, Adenis L, Cappelaere P, Demaille A. Pharmacokinetics of levamisole in healthy subjects and cancer patients. European Journal of Drug Metabolism and Pharmacokinetics 7, 247-54, 1982.

(18) Galtier P, Escoula L, Camguilhem R, Alvinerie M. Comparative bioavailability of levamisole in non lactating ewes and goats. Annales de Recherches Vétérinaires 12, 109-15, 1981.

Accepted for publication 27 December 1996. 